\title{
Estimation of Bosentan Monohydrate in Male Rabbit Plasma by using RP-HPLC Method
}

\author{
Revathi Mannam, Indira Muzib Yallamalli* \\ Institute of Pharmaceutical Technology, Sri Padmavati Mahila Visvavidyalaym (Women's University), Tirupati, India.
}

\begin{tabular}{|c|c|}
\hline ARTICLE INFO & ABSTRACT \\
\hline Article history: & \multirow{9}{*}{$\begin{array}{l}\text { A new method for the quantitative determination of bosentan monohydrate in male rabbit plasma was developed } \\
\text { by Reverse Phase HPLC as per standard regulatory guidelines. Precipitation method was used for extracting the } \\
\text { drug from the drug spiked plasma using mobile phase. The analyte extracted was injected in to ODS column } \\
\mathrm{C} 18(250 \mathrm{x} 4.6 \mathrm{~mm}, 5 \mu \mathrm{m}) \text {, temperature was maintained at } 25^{\circ} \mathrm{C} \text { and monitoring of effluent was performed at } \\
273 \mathrm{~nm} \text {. The mobile phase consist acetonitrile and phosphate buffer }(\mathrm{pH} 4.6) \text { in } 80: 20 \text { ratio. The method } \\
\text { developed shown high specificity for bosentan monohydrate. The calibration curve for bosentan monohydrate } \\
\text { was linear from } 0.1-5 \mu \mathrm{g} / 0.5 \mathrm{~mL} \text { in plasma }\left(\mathrm{R}^{2}=0.9999\right) \text {. The lower limit of detection is } 0.1 \mu \mathrm{g} / 0.5 \mathrm{~mL} \text {. Developed } \\
\text { method was verified for precision in intra-day and inter-day and was found within the limits. The accuracy of } \\
\text { the developed Reverse Phase HPLC method was found to be } 99.8 \pm 1.25-98.7 \pm 1.29 \% \text { and is found to be } \\
\text { reproducible. The method developed was proved to be adequate, sensitive and reproducible for the } \\
\text { determination of bosentan monohydrate in rabbit plasma. }\end{array}$} \\
\hline & \\
\hline & \\
\hline Availa & \\
\hline Key words: & \\
\hline Bosentan monohydrate, & \\
\hline Reverse Phase HPLC, ICH & \\
\hline guidelines, rabbit plasma, & \\
\hline $\begin{array}{l}\text { standard regulatory } \\
\text { guidelines. }\end{array}$ & \\
\hline
\end{tabular}

\section{INTRODUCTION}

Bosentan monohydrate is used as pulmonary arterial anti-hypertensive drug. It acts by blocking endothelien receptor $\mathrm{ET}_{1}$ and $\mathrm{ET}_{2}$ where their main action is constriction of pulmonary artery (Dermot et al., 2011, Christian et al., 2008). Bosentan monohydrate is chemically represented as 4-tert-butyl-N-[6- (2hydroxyethoxy)-5-(2-methoxyphenoxy)-2-pyrimidin-2-

ylpyrimidin-4-yl] benzenesulfonamide and its chemical formula is $\mathrm{C}_{27} \mathrm{H}_{29} \mathrm{~N}_{5} \mathrm{O}_{6} \mathrm{~S}$ (Figure 1) (National Centre for Biotechnology Information, 2017). Previous works reported analytical methods for the estimation of bosentan monohydrate in plasma. For the estimation of related substances in bosentan monohydrate RPHPLC method was developed (Jadhav et al., 2011). The reported methods are sensitive but are having disadvantages like a narrow

\footnotetext{
* Corresponding Author
}

Indira Muzib Yallamalli, Professor Institute of Pharmaceutical Technology Sri Padmavati Mahila Visvavidyalayam (Women's University), Tirupati-517502. INDIA. Email: yindira1415 @ gmail.com. range of linear response, more retention time and lesser precision. Two narrow-bore LC-MS methods were reported (Lausecker et al., 1995, Lausecker et al., 2000).

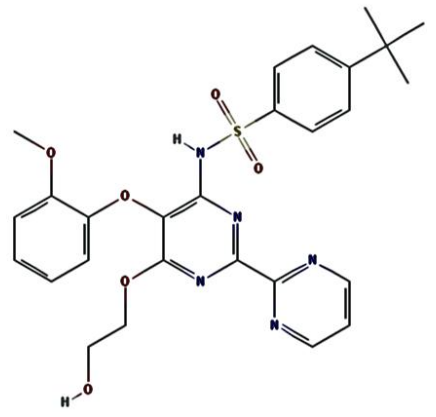

Fig. 1: Chemical structure of bosentan monohydrate.

The reported LC-MS methods involve costly detector and tiresome sample preparation steps. Our aim in the current research study is to develop a new RP-HPLC method for estimation of drug in New Zealand rabbit plasma which is very accurate \& sensitive. 


\section{MATERIALS AND METHODS}

\section{Chemicals and solvents}

Bosentan monohydrate and etodoloac were gift samples received from MSN laboratories, Hyderabad, India. HPLC grade Acetonitrile, HPLC grade Methanol and all other chemicals used were obtained from Merck chemical division, Mumbai. HPLC grade water was obtained from Milli-Q water purification system.

\section{Instrumentation}

Chromatography was performed using waters 2695 HPLC. The HPLC system contains high speed auto sampler, column oven, degasser and 2996 PDA detector. Isocratic pump mode was used in this system. Class Empower-2 software was used for monitoring the operations. The column used was ODS $\left(\mathrm{C}_{18} 250 \times 4.6 \mathrm{~mm}, 5 \mu \mathrm{L}\right)$ and the flow rate was $1 \mathrm{~mL} / \mathrm{min}$. The temperature of the column was set at $25^{\circ} \mathrm{C}$ and runtime was 10 min. The volume of injection loop was $20 \mu \mathrm{L}$ and the detection was done at the wave length of $273 \mathrm{~nm}$.

\section{HPLC conditions}

Both acetonitrile and phosphate buffer (containing 0.1\% orthophosphoric acid and $\mathrm{pH}$ was adjusted to 4.6 using triethanolamine) were filtered through $0.45 \mu \mathrm{m}$ membrane filter. The solvent system was pumped at the ratio of $80: 20 \mathrm{v} / \mathrm{v}$ to the column at a flow rate of $1 \mathrm{~mL} / \mathrm{min}$

\section{Preparation of phosphate buffer (pH 4.6)}

$7.0 \mathrm{~g}$ of potassium dihydrogen phosphate was taken in $1000 \mathrm{~mL}$ volumetric flask and $900 \mathrm{~mL}$ of HPLC grade water was added and stirred well. $100 \mathrm{~mL}$ of water was added and the $\mathrm{pH}$ was adjusted to 4.6 with $0.1 \%$ orthophosphoric acid and triethanolamine solution. Fresh buffer was used on each day.

\section{Preparation of mobile phase}

$200 \mathrm{~mL}$ of phosphate buffer $(\mathrm{pH} \mathrm{4.6)}$ and $800 \mathrm{~mL}$ of acetonitrile were taken in $1000 \mathrm{~mL}$ volumetric flask and degassed for $5 \mathrm{~min}$ using sonicator and the resultant mobile phase was filtered through $0.45 \mu$ membrane filter under vacuum. The same mobile phase was used as diluent.

\section{Preparation of standard solution}

$10 \mathrm{mg}$ of bosentan monohydrate was weighed accurately and transferred in to $100 \mathrm{~mL}$ volumetric flask. Ensured to dissolve the un-dissolved portions of drug by sonicating and final volume was made with mobile phase. Aliquot of $1 \mathrm{~mL}$ was taken and transferred into a $10 \mathrm{~mL}$ clean and dry volumetric flask and it was diluted up to the mark with the same diluent $(10 \mu \mathrm{g} / \mathrm{mL})$. From this $1 \mathrm{~mL}$ was taken and further diluted to $10 \mathrm{~mL}$ to get a concentration of $1 \mu \mathrm{g} / \mathrm{mL}$.

\section{Collection of blood samples from New Zealand rabbits}

Blood samples were collected in heparinized eppendroffs tube before administration of dosage form from left marginal ear vein of rabbit (CPCSEA No.:1677/PO/Re/S/2012/CPCSEA). From the blood cells plasma was separated by centrifuging blood at $8000 \mathrm{rpm}$ for $10 \mathrm{~min}$. The separated plasma was stored at $-20^{\circ} \mathrm{C}$ until further study.

\section{Extraction of drug from plasma of New Zealand rabbits}

$250 \mu \mathrm{L}$ of plasma containing varying amount of bosentan monohydrate was taken in to a teflon lined cap centrifuging tube followed by addition of $50 \mu \mathrm{L}$ of $2 \mu \mathrm{g} / 0.5 \mathrm{~mL}$ of etodoloac (internal standard) and $2 \mathrm{~mL}$ of acetonitrile. The mixture was vortexed for 2 min and centrifuged at $3300 \mathrm{rpm}$ speed until organic layer was separated. Organic layer was collected and filtered through $0.2 \mu \mathrm{m}$ membrane filter. $20 \mu \mathrm{L}$ of filtrate was injected into the analytical column and the eluents were observed at $273 \mathrm{~nm}$. The concentrations in the range of 0.1 to $5 \mu \mathrm{g} / 0.5 \mathrm{~mL}$ of plasma were prepared. The experiment was repeated for five times for all the concentrations.

\section{Validation}

The proposed RP-HPLC method was validated for linearity, precision and accuracy. The precision (\% coefficient of variation) was done by checking the inter-day and intra-day variation in the known drug concentration. The accuracy was done by estimating the percent recovery of known amount of drug added to the known amount of pre-analyzed bosentan monohydrate plasma sample (Validation of analytical procedure 1996, ICH guidelines 1996).

\section{Selectivity}

An aqueous mixture of bosentan monohydrate $(1 \mu \mathrm{g} / \mathrm{mL})$ was prepared and injected in to the column to determine the retention time of drug. A drug free plasma sample was chromatographed to observe any interfering peaks at the retention time of drug. Spiked plasma containing $1 \mu \mathrm{g} / 0.5 \mathrm{~mL}$ of bosentan monohydrate concentration was chromatographed to check the effect of various endogenous components in retention time (Ravichandran et al., 2010)

\section{Linearity}

The linearity of the proposed RP-HPLC method was determined in terms of the correlation coefficient. Calibration curve was taken in to consideration. The peak area ratios of bosentan monohydrate and etodoloac (internal standard) were recorded and the regression of the plasma concentration over its peak area ratio was calculated using the least square method of analysis. Mean of five samples was taken for linearity determination.

\section{Precision}

The precision of the method was done by spiking the plasma containing $0.2,0.5,1 \mu \mathrm{g} / 0.5 \mathrm{~mL}$ of bosentan monohydrate containing etodoloac $2 \mu \mathrm{g} / 0.5 \mathrm{~mL}$ (internal standard), intra-day and inter-day variations were observed using the RP-HPLC method developed. The results obtained were noted. Each sample was 
extracted from plasma as described previously. The precision of the developed method was calculated in terms of percent coefficient of variation. Mean of five samples was taken to determine the precision.

\section{Accuracy}

The accuracy of the developed RP-HPLC method was done by using recovery studies. Plasma samples containing different concentrations of drug $(0.2,0.5,1 \mu \mathrm{g}$ of bosentan monohydrate) was subjected to the developed method and each sample was injected three times. The difference in the measured concentration and that of the added quantity was expressed in terms of percent recovery (Peter et al., 2007, ICH 2005).

\section{RESULTS AND DISCUSSION}

\section{Standard calibration curve}

The standard calibration curve of peak area ratios of bosentan monohydrate to etodoloac in rabbit plasma was found to be linear (Figure 2). Various peak area ratios of bosentan monohydrate to etodoloac against the concentration of drug was also reported (Table 1).

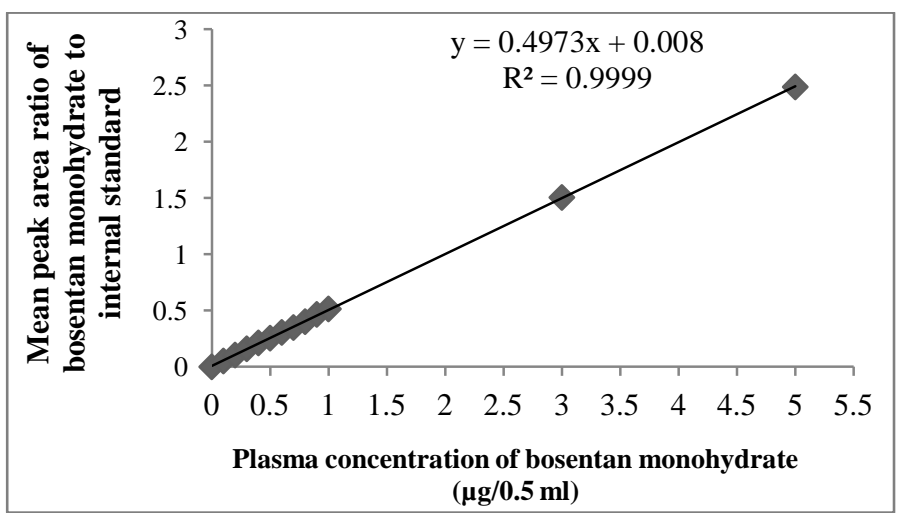

Fig. 2: Standard graph for the estimation of bosentan monohydrate in rabbit plasma

Table 1: Calibration of the RP-HPLC method for the estimation of bosentan monohydrate in rabbit plasma.

\begin{tabular}{ccc}
\hline $\begin{array}{c}\text { Plasma concentration of bosentan } \\
\text { monohydrate }(\boldsymbol{\mu g} / \mathbf{0 . 5} \mathbf{m L})\end{array}$ & $\begin{array}{c}\text { Peak area } \\
\text { ratios* }\end{array}$ & $\% \mathbf{C . V}$. \\
0 & 0 & 0 \\
0.1 & 0.052007 & 0.15 \\
0.2 & 0.104633 & 0.05 \\
0.3 & 0.160475 & 0.17 \\
0.4 & 0.212688 & 0.03 \\
0.5 & 0.254922 & 0.28 \\
0.6 & 0.306102 & 0.47 \\
0.7 & 0.349369 & 0.51 \\
0.8 & 0.401659 & 0.42 \\
0.9 & 0.466127 & 0.18 \\
1 & 0.514828 & 0.51 \\
3 & 1.505902 & 0.70 \\
5 & 2.488393 & 0.47 \\
\hline
\end{tabular}

*Mean of five determinations

\section{Selectivity}

The method was set with a run time of the 10 minutes. The retention time for bosentan monohydrate and etodoloac were 3.6 minutes and 4.1 minutes respectively and was depicted in model chromatogram (Figure 3). The same bosentan monohydrate solution containing internal standard was injected for five times the retention time was found to be same. Blank chromatogram of plain plasma was also provided (Figure 4).

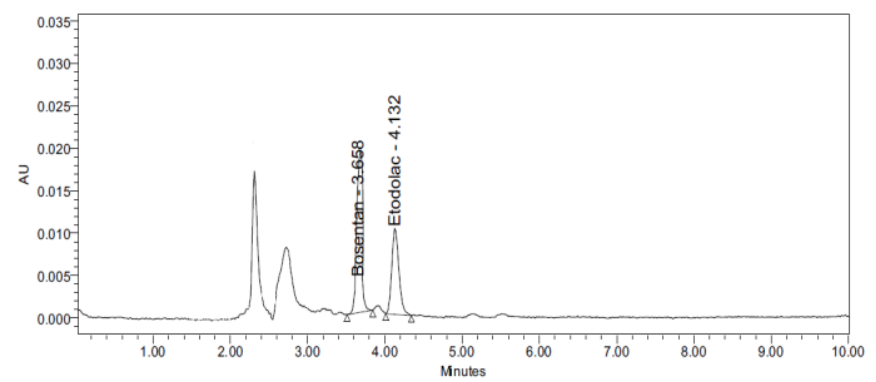

Fig. 3: A model chromatogram for estimation of bosentan monohydrate in rabbit plasma.

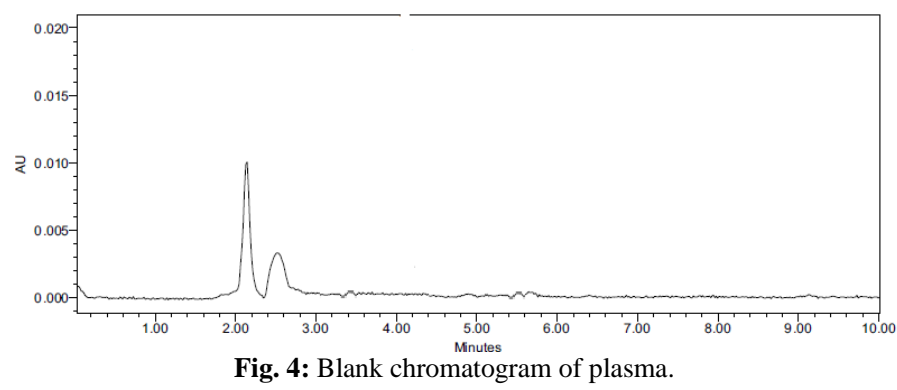

\section{Linearity}

The peak area ratios of bosentan monohydrate to internal standard were reproducible which is also indicated by low coefficient of variation (0.03) (Table 1). The statistical analysis results by least square method confirmed a high correlation coefficient of 0.9999 in the range of 0.1 to $5 \mu \mathrm{g} / 0.5 \mathrm{~mL}$ (Figure 2) for the plasma concentration of bosentan monohydrate and its respective peak area ratios. The regression equation was found to be $\mathrm{Y}=0.4973 \mathrm{X}+0.008$ for bosentan monohydrate concentration over its peak area ratio with internal standard where $\mathrm{Y}$ is the peak area ratio and $\mathrm{X}$ is the concentration of bosentan monohydrate. By using the regression equation estimation of the bosentan monohydrate in plasma or in validation study can be done. The lower limit of detection is $0.1 \mu \mathrm{g} / 0.5 \mathrm{~mL}$.

\section{Precision}

The present RP-HPLC method was also validated for intra-day and inter-day variation. The plasma samples containing drug $(0.2,0.5,1 \mu \mathrm{g} / 0.5 \mathrm{~mL})$ were extracted as per the procedure described previously, and the resultant filtrate samples were repeatedly injected on the same day and on three different days. The coefficient of variation (CV) was calculated in the peak area of bosentan monohydrate for five replicate injections which was 
found to be less than $1.4 \%$. The inter-day variation ( 3 days and five injections) was found to be less than $1.4 \%$ and the results were reported (Table 2). Thus the present RP-HPLC method was proved to be highly reproducible and it was confirmed by the results.

Table 2: Inter-day and intra-day precision for the estimation of bosentan monohydrate in rabbit plasma.

\begin{tabular}{|c|c|c|c|c|c|c|}
\hline \multirow{2}{*}{ 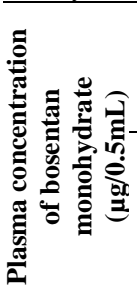 } & \multicolumn{3}{|c|}{$\begin{array}{c}\text { Concentration of bosentan } \\
\text { monohydrate }(\mu \mathrm{g} / 0.5 \mathrm{~mL}) \\
\text { found } \\
\text { (Intra-day) }\end{array}$} & \multicolumn{3}{|c|}{$\begin{array}{c}\text { Concentration of } \\
\text { bosentan monohydrate } \\
(\mu \mathrm{g} / 0.5 \mathrm{~mL}) \text { found } \\
(\text { Inter-day })\end{array}$} \\
\hline & Mean* & $\begin{array}{c}\% \\
\mathrm{CV}\end{array}$ & $\begin{array}{c}\% \\
\text { Precision }\end{array}$ & Mean* & $\begin{array}{c}\% \\
\mathrm{CV}\end{array}$ & $\begin{array}{c}\% \\
\text { Precision }\end{array}$ \\
\hline 0.2 & 0.198 & 1.2 & $99.2 \pm 1.2$ & 0.195 & 1.4 & $97.5 \pm 1.4$ \\
\hline 0.5 & 0.499 & 1.1 & $99.8 \pm 1.1$ & 0.496 & 1.2 & $99.2 \pm 1.2$ \\
\hline 1 & 0.999 & 1.4 & $99.9 \pm 1.4$ & 0.994 & 1.2 & $99.4 \pm 1.2$ \\
\hline
\end{tabular}

* Mean of five determinations.

\section{Accuracy}

When a known amount of bosentan monohydrate (0.2, $0.5,1 \mu \mathrm{g})$ was added to pre analyzed plasma samples $(1 \mu \mathrm{g} / 0.5 \mathrm{~mL})$, there was a high recovery $(99.8 \pm 1.25 \%)$ of the drug indicating that this RP-HPLC method is highly accurate and the results were reported (Table 3 ).

Table 3: Recovery of bosentan monohydrate after adding known amounts to pre-analyzed plasma samples $(1 \mu \mathrm{g} / 0.5 \mathrm{~mL})$.

\begin{tabular}{ccc}
$\begin{array}{c}\text { Amount of bosentan } \\
\text { monohydrate added }(\boldsymbol{\mu g})\end{array}$ & $\begin{array}{c}* \text { Mean } \pm \text { SD amount } \\
(\boldsymbol{\mu g}) \text { recovered }\end{array}$ & $\begin{array}{c}\% \\
\text { Recovery }\end{array}$ \\
\hline 0.2 & $0.197 \pm 0.07$ & $98.5 \pm 1.31$ \\
0.5 & $0.499 \pm 0.16$ & $99.8 \pm 1.25$ \\
1 & $0.987 \pm 0.19$ & $98.7 \pm 1.29$ \\
\hline
\end{tabular}

*Mean of three determinations.

\section{CONCLUSION}

The present RP-HPLC method described above is found to be precise, simple and highly accurate for the estimation of bosentan monohydrate in rabbit plasma samples. The Reverse Phase-HPLC method developed was validated as per standard regulatory guidelines and all the parameters satisfied prerequisites of robust and accurate method. Hence, adopting this method for quality control analysis of the bosentan monohydrate in rabbit plasma is confirmed.

\section{ACKNOWLEDGEMENTS}

Authors would like to thank DST-CURIE, SPMVV for their technical support in Modern Instrumentation facilities, Institute of pharmaceutical technology, SPMVV for providing the advanced lab facilities.

Financial support and sponsorship: The research work was financially supported by UGC-BSR-RFSMS (Ref no. F.7346/2011).
Conflict of Interests: There are no conflicts of interest.

\section{REFERENCES}

Christian FO, Ralf E, Wilhelm K, David P. Inhibition of endothelin receptors in the treatment of pulmonary arterial hypertension: does selectivity matter. Eur Heart J, 2008; 29(16): 1936-1948.

Dermot S O'Callaghan, Laurent S, David M, Xavier J, Olivier S, Gerald S, Marc H. Treatment of pulmonary arterial hypertension with targeted therapies. Nature reviews/cardiology, 2011; 8: 526-538.

Humbert M, Barst RJ, Robbins IM, Channick RN, Galie N, Boonstra A, Rubin LJ, Horn EM, Manes A, Simonneau G. Combination of bosentan with epoprostenol in pulmonary arterial hypertension: BREATHE-2. Eur Respir J, 2004, 24(3):353-359.

$\mathrm{ICH}$, Validation of analytical procedure, text and methodology Q2 (R1), International conference on Harmonization, IFPMA,Geneva, Switzerland, 2005.

International conference on harmonization of technical requirements for registration of pharmaceuticals for human ICH harmonized tripartite guidelines validation of analytical procedures, Text and methodology Q2 (R1), 6 November 1996.

Jadhav SA, Landge SB, Jadhav SL, Niphade NC. Stabilityindicating gradient RP-LC method for the determination of process and degradation impurities in bosentan monohydrate: An endothelin receptor antagonist. Chromatography Research International, 2011, Article ID 929876: 1-5.

Lausecker B, Hess B, Fischer G, Mueller M, Hopfgartner G. Simultaneous determination of bosentan and its three major metabolites in various biological matrices and species using narrow bore liquid chromatography with ion spray tandem mass spectrometric detection. Journal of Chromatography B: Biomedical Science and Application, 2000, 749(1): 67-83.

Lausecker B, Hopfgartner G. Determination of an endothelin receptor antagonist in human plasma by narrow bore liquid chromatography and ion spray tandem massspectrometry. Journal of Chromatography A, 1995, 712(1): 75-83.

National Center for Biotechnology Information. PubChem Compound Database; CID $=104865$. Available at: https://pubchem.ncbi.nlm.nih.gov/compound/104865 (accessed July 9, 2017).

Peters FT, Drummer OH, Musshoff F. Validation of new methods. Forensic science international, 2007; 165(2):216-24

Ravichandran V, Shalini S, Sundram KM, Harish R. Validation of anlyatical methods- strategies and importance. Int $\mathrm{J}$ Pharmacy and pharm Sci, 2010; 2(3): 18-22.

Validation of analytical procedure: Methodology Q2B, ICH Harmonized Tripartite Guidelines, 1996; 1-8.

How to cite this article:

Mannam R, Yallamalli IM. Estimation of Bosentan Monohydrate in Male Rabbit Plasma by Using Rp-Hplc Method. J App Pharm Sci, 2017; 7 (11): 106-109. 